\title{
Germano F.E. Melchert, médico e político: Trajetória pública de um imigrante alemão no Brasil da Primeira República
}

\author{
Valquiria Maria Augusti*
}

\begin{abstract}
RESUMO: O presente artigo visa apresentar, em linhas gerais, as estratégias pelas quais alguns imigrantes conseguiram uma rápida inserção social na sociedade brasileira. Para atingir tal objetivo foram realizados o levantamento e a análise de diversas fontes históricas relacionadas à trajetória pública do imigrante alemão Germano F.E. Melchert. É possível identificar, no final do século XIX, que algumas das transformações ocorridas na cidade de Campinas levaram à abertura do espaço político a determinados imigrantes que já estavam integrados à sociedade campineira e que de alguma forma mantinham estreitas relações com os políticos locais. No entanto, há que se considerar que essa inserção ocorreu devido à formação universitária desses imigrantes na área de saúde (médicos).
\end{abstract}

Palavras-chave: Imigração, política, Campinas (história), educação, saúde

\section{Introdução}

O delineamento deste trabalho se deu a partir do projeto "Família, imigração e cultura - Os alemães (1950-1980)", desenvolvido no Centro de Memória da Unicamp, sob coordenação da professora doutora Olga Rodrigues de Moraes von Simson, cujo objetivo principal foi o estudo do processo de inserção dos imigrantes de língua e cultura alemãs na sociedade brasileira, através da história de vida de três gerações de famílias fixadas nas zonas rural

* Professa no ISCA (Instituto de Ciências Aplicadas de Limeira), cursos Serviço Social e Ciências Sociais, e mestranda pelo Programa de Pós-graduação da Faculdade de Educação da Unimep. E-mail: vaugusti@uol.com.b 
e urbana de Campinas. Para selecionar as famílias, cuja trajetória de vida seria investigada, tomamos como referência os resultados do projeto integrado "Educação, lazer e consumo cultural de famílias imigrantes em cidades em rápida transformação social - São Paulo e Campinas, 1850-1950" .

Dentre essas famílias, chamou-nos a atenção a trajetória pública de um indivíduo - Germano Melchert, imigrante, alemão, médico e que, por todas essas qualidades conjugadas, teve participação ativa na política local campineira no final do século XIX, assumindo cargos públicos que eram na sua maioria restritos aos membros das famílias tradicionais das elites campineiras. Constatamos, a partir das pesquisas desenvolvidas no projeto acima citado, que os imigrantes de língua e cultura alemãs que se fixaram na cidade de Campinas tiveram uma inserção muito mais rápida na sociedade brasileira do que aqueles que se fixaram em Friburgo, bairro rural dessa mesma cidade. Essa questão pode ser percebida tanto pelos casamentos, que na terceira geração já eram realizados independentemente da etnia à qual o cônjuge pertencia, quanto pela participação política desses imigrantes e descendentes em cargos públicos em Campinas.

No caso de Friburgo, os casamentos dentro do grupo e a manutenção da língua e de valores alemães foram balizados pela preocupação com a Deutschum (germanidade).

Os estudos sobre o tema imigração européia (falamos particularmente dos imigrantes de língua e cultura alemãs) indicam que os imigrantes germânicos que se estabeleceram no sul do país e no estado de São Paulo criaram associações com o intuito de resolver questões práticas, tais como: a falta de escolas, de igreja e de espaços de lazer. Amaral Lapa, em seu livro $A$ cidade: Os cantos e os antros: Campinas 1850-1900, discute essa questão acrescentando que as associações funcionaram como estratégia de solidariedade e de preservação dos valores, nesse caso, germânicos. Em suas palavras:

Há uma face implícita ou explícita de prática social de emulação e competição, geradora de formas de resistência e combate destinadas a assegurar a sobrevivência e a reprodução de categorias e grupos que se dirigem para a luta de classes.

Mesmo no interior das classes ocorrem esses comportamentos e atitudes. Uma hipótese viável nesse sentido é a de que essa tendência ao 
associativismo foi de certa maneira provocada pela marcante presença estrangeira de imigrantes no município, que viam nesse movimento uma estratégia de solidariedade e preservação de valores, mostrando-se muito eficientes e com capacidade de iniciativa nesse sentido. (Lapa 1996, p. 50)

Nossa proposta, portanto, é indicar como a formação educacional foi um dos elementos centrais no estabelecimento das relações de caráter econômico, social e político e se configura como uma das estratégias dos imigrantes nesse processo de inserção na sociedade brasileira. Essa investigação será feita acompanhando a trajetória do médico Germano Frederico Eduardo Melchert.

\section{A vida pública: Medicina e política}

Olga Melchert escreveu, em 1966, a biografia de seu pai - Germano F.E. Melchert. Conta que seus avós, com cinco filhos e mais outro membro da família, desembarcaram em 7 de setembro de 1856, no Porto de Santos, vindos da atual Alemanha. Indagando sobre as razões pelas quais eles emigraram, afirma:

Era no tempo que a Alemanha em sua divisão contava com o ducado de Holstein, o qual foi causa de guerra com a Dinamarca que disputava a posse do ducado.

Os membros da família que para aqui vieram eram Cavalheiros "Ritter" aliados ao duque de Holstein que lutaram e despenderam todos os seus haveres para mantê-lo, que finalmente ficou para a Alemanha. Foi portanto uma questão política que motivou a retirada dos três irmãos Melchert de sua pátria.

Em linhas gerais, os temas abordados nessa biografia são: a história da vinda da família ao Brasil; a trajetória escolar de seu pai; o casamento; sua atuação profissional no período das epidemias em Campinas; o reconhecimento do povo campineiro quanto a sua atuação como médico. Mas o que diz Olga Melchert sobre a participação de seu pai na política campineira? A biografia não traz informações sobre a vida política do Dr. Melchert - a ênfase é dada a sua participação como médico na cidade e região. 
Ao investigarmos sua trajetória pública, deparamos como uma situação ímpar, mas não de todo irregular em Campinas - a presença, no período compreendido entre a metade e o final do século XIX, de imigrantes de diferentes nacionalidades na câmara de vereadores - entre eles Germano F.E. Melchert.

Germano Frederico Eduardo Melchert nasceu em 2/1/1844, na cidade de Flemhude (Holstein), Alemanha, e imigrou, como já dissemos, com seus pais para o Brasil em $1856 \mathrm{com}$ a idade de 12 anos. Em 1868 retornou à Alemanha para estudar medicina na Real Universidade "Maximiliano Ludwig II", Munich, Baviera. Entre 1870 e 1872, Germano F.E. Melchert serviu como médico voluntário para a Alemanha na guerra contra a França. Para atuar profissionalmente como médico no Brasil, defendeu tese em 1874 na Faculdade Imperial de Medicina do Rio de Janeiro. Nesse mesmo ano mudouse para Campinas e começou a atender na Rua do Rosário, 66. Nos Almanaques da cidade de Campinas, anuncia que atende na sua "Casa de Saúde", mas que clinica também em cidades vizinhas - Porto Feliz e Piracicaba (cf. Britto 1955, p. 168). Seis anos depois, em 24 de abril de 1880, foi nomeado, pelo Imperador Pedro II, Capitão Cirurgião-Mor (cargo extinto em 1828, segundo Machado 1978, p. 155) do Comando Superior da Guarda Nacional dos comandos de Campinas e Jundiaí.

É interessante observar que nos Registros de Casamentos de Acatólicos - de 1864 a 1889 - da Câmara Municipal de Campinas consta um número significativo de matrimônios intra-étnicos, entre eles o de Germano F.E. Melchert (súdito do Império Alemão) com Maria Catharina Elisabeth Wiebeck (súdita do Império Alemão), em 1875. Entre outras informações retiradas dessa fonte observamos que as testemunhas presentes em seu casamento eram membros da colônia alemã (denominação utilizada na época, pelos indivíduos de língua e cultura alemãs que viviam no espaço citadino, quando anunciavam as festas promovidas no clube e nas escolas alemãs) e, portanto, ambas as famílias circulavam entre os imigrantes da cidade: "O acto religioso foi celebrado no dia primeiro de maio de mil oitocentos e setenta e cinco, oito horas da tarde em Campinas, na casa do senr. Guilherme Wiebeck Rua de São João n.76 em presença das testemunhas Jacob Bolliger e Theodoro Jahn."

Germano Melchert, imigrante alemão, passou por quais "filtros" para ocupar os cargos públicos abaixo relacionados? Ele foi suplente de juiz municipal em 1873, suplente de delegado em 1877, delegado no período de 1877 a 1881, membro do Conselho de Intendentes em 1891. Um ano depois, é citado como um dos diretores do Partido Municipal, que foi fundado em 1892, 
ano em que é eleito vereador na primeira Câmara do regime republicano 1892-1895) com mandato de três anos.

No Diário de Campinas de 12 de outubro de 1890, Dr. Germano Melchert é relacionado como um dos "capitalistas" de $5^{\mathrm{a}}$ classe em débito com a Intendência Municipal. Alguns indícios - "capitalista de $5^{\mathrm{a}}$ classe" (pessoa que emprestava dinheiro, chamado atualmente de agiota) e proprietário de uma "Casa de Saúde" (enfermarias particulares) - compõem um quadro passível de explicar o fato de esse imigrante ter tido a possibilidade de ingressar na vereança campineira. Segundo Machado (1978, pp. 154-156), os médicos travaram no Brasil, na primeira metade do século XIX, um longo debate em relação à política. Tentavam mostrar que a medicina era a propiciadora da saúde aos cidadãos e que esta poderia contribuir para o engrandecimento da pátria. Defendiam a inclusão dos médicos nas Câmaras Municipais para tornar eficazes as medidas de higiene pública e política médica. Nesse contexto, o saber médico colocava-se em pauta e penetrava cada vez mais nos espaços de poder da sociedade brasileira associando-se ao Estado:

O século XIX assinala para o Brasil o início de um processo de transformação política e econômica que atinge igualmente o âmbito da medicina, inaugurando duas de suas características, que não só têm vigorado até o presente, como tem-se intensificado cada vez mais: a penetração da medicina na sociedade, que incorpora o meio urbano como alvo da reflexão e da prática médica, e a situação da medicina como apoio científico indispensável ao exercício de poder do Estado. (Machado 1978, p. 155)

Nesse contexto, quando Germano F.E. Melchert assume o cargo de suplente de juiz municipal em 1873, alguns imigrantes - já naturalizados haviam conseguido espaço dentro da política local. Entre eles o farmacêutico Theodoro Langgaard, que legislará como vereador no período de 1857 a 1860.

Com base nas idéias expostas anteriormente, podemos inferir que a trajetória pública desse imigrante deveu-se a uma confluência de fatores, tais como: o papel da medicina na produção de um discurso que abriu espaço porque pressupunha práticas de intervenção - nas Câmaras Municipais para os profissionais da área de saúde e higiene e, por outro lado, a questão econômica - 0 "capitalista" (mesmo que de $5^{\mathrm{a}}$ classe) se achava numa situação privilegiada pelas relações que estabelecia com a elite campineira. 


\title{
Eleitos e eleitores na Campinas da segunda metade do século XIX
}

Para o estudo da trajetória pública desse imigrante alemão, filho de grande proprietário rural, tornou-se necessário apresentar, em linhas gerais, qual o contexto histórico em que se deu sua participação na política campineira.

Nesse sentido, os trabalhos de Magalhães (1992) e Telarolli (1981) trouxeram informações básicas que elucidaram as questões relativas ao poder local no período de 1870 a 1895 . Magalhães (1992, p. 11) considera que: "[a] questão do ingresso nas instâncias de poder passava, necessária e notoriamente, pelos canais da propriedade territorial e das formações oligárquicas...". Ao identificar os personagens que participam da estrutura política de Campinas, caracterizá-los socialmente e explicitar seus troncos familiares, conclui:

\begin{abstract}
À frente de propriedades rurais do tipo "tradicional" - grandes fazendas monocultoras que visavam o mercado externo - estavam proprietários envolvidos em transações mercantis e financeiras. Parte de seu capital era investido em empresas de telégrafo, transportes e outros setores ligados às atividades secundárias e terciárias da economia. A economia rural, baseada na dicotomia senhores/escravos, convivia com uma sociedade em processo de diversificação no espaço urbano.
\end{abstract}

Essa conjuntura levou a uma redefinição da função da cidade, de sua relação com o campo e também das relações de mando. O poder público local, através da Câmara Municipal, da polícia, dos juízes, entre outros, passou a "filtrar" tanto o poder governamental quanto o poder privado local, seja aceitando as nomeações ou eleições de pessoas estrangeiras às principais parentelas, seja unindo representantes dos poderes público e privado, através das ligações familiares. (Magalhães 1992, p. 15,grifos meus)

O espaço social passou, na segunda metade do século XIX, por transformações estruturais que alteraram os parâmetros para a integração e a ascensão política. A admissão de "pessoas estrangeiras" às principais "parentelas" tornou-se necessária como estratégia para garantir os interesses dos cafeicultores? Como se articularam os interesses dos comerciantes e profissionais liberais com os da elite agrária campineira? 
No auge da economia cafeeira, principalmente a partir de 1870 , Campinas apresentava um desenvolvimento intenso do comércio interno o que levou a uma reorganização do espaço urbano e da política.

Os critérios e limites para participação como eleito e eleitor, no entanto, continuaram sendo restritivos à grande maioria dos cidadãos que deveriam possuir, em 1881, determinadas "qualidades", tais como: se fosse acatólico deveria comprovar renda anual superior a $200 \$ 00$ (duzentos réis); no caso dos imigrantes, ter-se naturalizado há mais de seis anos. Excluíam-se do universo da cidadania os negros libertos, os escravos, os analfabetos (que eram maioria), os imigrantes não-naturalizados e as mulheres.

Logo após a Proclamação da República o Governo Provisório extinguiu a exigência da renda mínima para o eleitor, mas este teria que ser maior de 21 anos e alfabetizado. Entre 1850 e 1890 a população de Campinas ligada à agricultura por vínculos de trabalho foi minoria nas eleições, indicando talvez o alto índice de analfabetismo se considerarmos que a cidade teve um elevado percentual de escravos que, depois de 1888, tornaram-se libertos mas não tinham acesso à educação. Portanto, ainda continuavam "impedidos" de participar como eleitos ou eleitores.

Em relação aos estrangeiros, rezava a Constituição de 1891, como indica Telarolli (1981, p. 448), que:

(...) embora nascidos no exterior, a Constituição reconhecia como cidadão brasileiros. Entre outros estiveram, no caso, os da grande naturalização, ou seja, os estrangeiros que a 15 de novembro de 1889, estando no Brasil, não declarassem no prazo de seis meses após entrar em vigor a Constituição, o interesse em conservar a nacionalidade de origem e os estrangeiros que possuíssem bens imóveis no Brasil e fossem casados com brasileiros, a não ser que manifestassem a intenção de não mudar de nacionalidade. Também considerava brasileiros os que por outro modo se naturalizassem. (grifos meus)

A porcentagem de participação de estrangeiros na política pública campineira, no período em questão, não sofreu grandes alterações, como pudemos observar nas relações de eleitores e eleitos que constam nos periódicos da cidade. 


\section{Dr. Germano E.F. Melchert - Legislatura de 1892 a 1895}

Levantamos o conteúdo das discussões, que foram feitas pelos vereadores da Câmara Municipal de Campinas, no período que o Dr. Melchert foi Intendente Municipal (1892 a 1895), com o objetivo de recuperar o teor de sua atuação política. Ao estudar a trajetória pública desse indivíduo percebemos que se abriram inúmeras possibilidades de investigação, tais como: a extensão dos interesses do poder público na cidade de Campinas; o direcionamento das intervenções propostas pelos vereadores por meio da elaboração de posturas; o grau de inserção do imigrante por intermédio da participação política e a definição de critérios de cidadania. A fim de explicitar quais eram as preocupações do poder público, no período de 1892 a 1895, selecionamos alguns temas abordados com maior freqüência nas discussões da Intendência Municipal de Campinas:

- projeto de Regimento Interno da Câmara Municipal de Campinas;

- saneamento da cidade;

- instalação de iluminação elétrica;

- impostos sobre transporte e propriedade;

- posturas relativas às doenças infecciosas;

- empréstimo para instalação da "Companhia Canil Agrícola Funilense" (estrada de ferro).

A discussão sobre o projeto de Regimento Interno da Câmara de Campinas, apresentada por seu presidente na Sessão Ordinária de 3 de outubro de 1892, é aprovada após algumas alterações propostas pela comissão que estudou o projeto, composta pelos vereadores Dr. Melchert, José Bueno Lapa e José Falque em 5 de outubro de 1892. Entre as alterações propostas estava a da criação de uma comissão de "Hygiene e Instrução Pública" cujos membros foram eleitos em 6 de outubro de 1892, sob a presidência de Antonio Lobo tendo como um de seus integrantes o Dr. Melchert.

Outro tema presente nas atas dizia respeito à preocupação com relação à questão sanitária na cidade em virtude das várias epidemias que haviam ocorrido naquele período, como podemos observar no discurso do intendente Ricardo Coelho: "Considerando que o trabalho sanitário nesta cidade é urgente e representa um serviço de salvação pública, attendendo-se a approximação da estação calorosa; considerando que, nomeado o Intendente de Hygiene, deve este não encontrar embaraços em sua acção..." Na Sessão Especial de 30 de outubro de 1892, o Dr. Melchert apresentou uma proposta, aprovada em 
31 de outubro de 1892, de consignação no orçamento de uma verba para instalação de forno para incineração do lixo, o que indica a sua preocupação com questões relativas à higiene pública.

O apoio do poder público local ao empréstimo à Companhia Funilense, com juros fixados em $6 \%$ ao ano e pelo prazo de 20 anos, apoiava-se na argumentação de que a estrada de ferro seria de grande utilidade pública. Para o presidente da Câmara - Antonio Lobo -, seria esta uma medida que facilitaria o transporte, tendo como conseqüência o engrandecimento da cidade. Segundo ele, com a implantação da Funilense: “(...) seguir-se-á incontestavelmente o desenvolvimento da zona por ella percorrida; nestas condições entende, pois, que a indústria agrícola não poderá ter êxito sem a facilidade de communicação e mais que essa empresa vem satisfaser uma necessidade do município."

No entanto, para o Dr. Melchert: “(...) a Câmara não deve e nem Ihe convém fazer tal empréstimo, porque tem de attender a serviços municipaes de importância e não pode, conseguintemente, distrahir uma quantia avultanda como é essa."

Sabemos hoje que a Estrada de Ferro Funilense foi construída e favoreceu os fazendeiros de café do "oeste paulista" e, por conseqüência, o crescimento da cidade de Campinas.

Porém, a cidade havia sofrido com a epidemia de febre amarela em 1889. Necessitava urgentemente de medidas de saneamento que contivessem o alastramento das doenças - em especial da febre amarela. Talvez, ao considerar "avultanda" a verba para o empréstimo, Dr. Melchert estivesse preocupado com outros "serviços municipaes" que não eram uma preocupação de toda Câmara, e muito menos do presidente da Intendência de "Hygiene e Instrução Pública". Denota uma preocupação com os problemas da sociedade campineira em geral e não com os interesses dos fazendeiros locais. $O$ exame da participação desse imigrante na vida legislativa da cidade demonstra:

- aceitação, pelos elementos ligados ao poder legislativo, de sua competência e pertencimento à sociedade local;

- uma preocupação, por parte dele, com os problemas mais contundentes vividos pela cidade no que concerne principalmente à área de saúde;

- atitudes tentando evitar o uso do dinheiro público em benefício dos grandes proprietários rurais.

Enfim, ao propormos o estudo da trajetória do Dr. Melchert na vida pública tínhamos em mãos diversas fontes, das quais nos valemos, com o intuito de 
entender as estratégias pelas quais os imigrantes conseguiram uma rápida inserção social na sociedade brasileira. Percebemos que, nesse período, algumas transformações que ocorreram na cidade de Campinas levaram à abertura do espaço político a determinados imigrantes que já estavam integrados à sociedade campineira e que de alguma forma mantinham estreitas relações com os políticos locais. Na sua maioria, tais imigrantes vinham de famílias abastadas e sua formação educacional superior foi realizada em escolas no exterior ou no próprio país nas áreas de medicina e direito.

Germano F.E. Melchert, Doctor and political: A German immigrant's public trajectory in Brazil of the First Republic

ABSTRACT: This article presents the strategies for the which some immigrants got a fast social insert in the Brazilian society. We analyzed several historical sources that count the German immigrant's related public trajectory Germano F.E. Melchert. Are possible to identify, in the end of the century XIX, that some of the transformations happened in the city of Campinas took to the opening of the political space for immigrants that were already integrated into the society and that in some way maintained narrow relationships with the politicians of the city. However, we have to consider that this insert happened because Germano F.E. Melchert had a university formation in the area of health. He was medical.

\section{Referências bibliográficas}

BRITTO, Jolumá. História da cidade de Campinas. Campinas: Saraiva, 1955, vol. 2.

LAPA, José Roberto do Amaral. A cidade: Os cantos e os antros: Campinas 1850-1900. São Paulo: Editora da USP, 1996.

MACHADO, Roberto. Danação da norma: A medicina social e constituição da psiquiatria no Brasil. Rio de Janeiro: Edições Graal, 1978.

MAGALHÃES, Wanda Moreira. "Eleitores e eleitos: Os agentes do poder em Campinas, na segunda metade do século XIX". Tese de doutorado em História São Paulo: USP, 1992.

RELATÓRIO DO PROJETO INTEGRADO. "Educação, lazer e consumo cultural de famílias imigrantes em cidades em rápida transformação social - 
São Paulo e Campinas, 1850-1950". Período de 1991 a 1994, CMUUnicamp e do Ceru-USP/CNPq. Coordenação: Professora doutora Olga Rodrigues de Moraes von Simson.

SEYFERTH, Giralda. "A identidade teuto-brasileira numa perspectiva histórica". In: MAUCH, Cláudia e VASCONCELLOS, Naira (orgs.). Os alemães no sul do Brasil: Cultura, etnicidade e história. Canoas: Ulbra, 1994.

TELAROLLI, Rodolfo. "A organização municipal e o poder local no estado de São Paulo na Primeira República”. Tese de Doutorado. São Paulo: FFLCH-USP, 1981.

\section{Fontes históricas de referência:}

Dr. Germano Melchert - Biografia escrita em 1996, cedida por Glória Melchert, sobrinha de Olga Melchert, em entrevista realizada com a equipe do Projeto "Família, imigração e cultura - Os alemães (1950-1980)". Campinas: Centro de Memória da Unicamp/1996.

Almanak de Campinas para o anno de 1873, organizado e publicado por José Maria Lisboa, Anno III, Campinas: Typ. Gazeta de Campinas, 1872.

Almanach de Campinas, litterario e estatistico. Campinas: Typographia Cardona, 1892.

Diário de Campinas. Domingo, 12 de outubro de 1890.

Livro de Actas da Intendência Municipal - de 12 de junho de 1892 a 9 de abril de 1894 - Campinas - São Paulo.

Processo do Tribunal de Justiça de Campinas $-2^{0}$ ofício - $\mathrm{n}^{\circ} 8.253$ - cx. 4161886 - Germano Melchert - Cassiano B.R. Gonzaga - embargo.

Registro de Certidão de Casamento $-\mathrm{n}^{0} 118$, in: "Livro de Registro de casamentos acatólicos realisados nesta cidade - Campinas - 18691889". 